\title{
Do health policies address the availability, accessibility, acceptability, and quality of human resources for health?: Analysis of three decades of National Health Policy of India
}

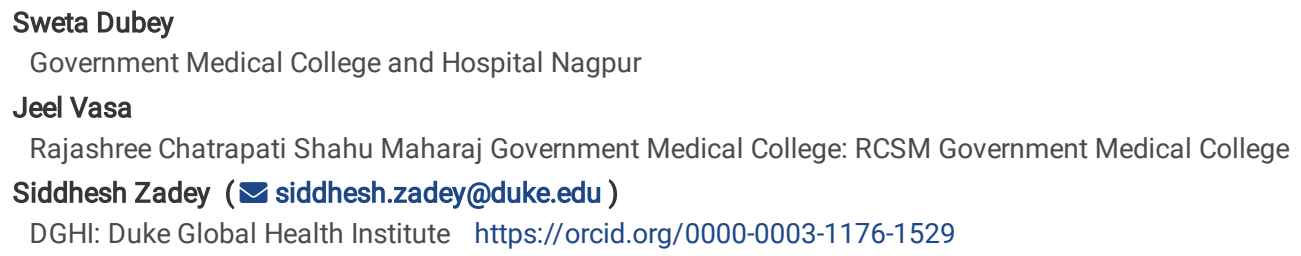

\section{Research}

Keywords: Human resources for health, India, policy analysis, health system strengthening, deficit indices, national health policy

Posted Date: November 25th, 2020

DOI: https://doi.org/10.21203/rs.3.rs-113315/v1

License: @ (i) This work is licensed under a Creative Commons Attribution 4.0 International License. Read Full License 


\section{Abstract}

Background: Human Resources for Health $(\mathrm{HRH})$ are crucial to improve health services coverage and population health outcomes. The World Health Organisation (WHO) promotes four dimensions - availability, accessibility, acceptability, and quality (AAAQ) for HRH strengthening. Integrating AAAQ dimensions in policymaking is essential to reduce the critical shortage of $\mathrm{HRH}$ in India.

Methods: We created a multilevel framework to evaluate the incorporation of AAAQ dimensions along with strategies and actions that can improve them in $\mathrm{HRH}$-related policies. HRH-related recommendations of all versions of the National Health Policy of India (NHPI) were classified according to targeted dimensions and cadres. We evaluated the extent to which NHPIs incorporated AAAQ dimensions over three decades. Furthermore, dimension-wise normalized indices were formulated to calculate HRH deficits for pre-NHPI years to assess situational deficiencies. Finally, we evaluated whether or not the HRH recommendations of NHPIs addressed the deficient cadres and dimensions for the corresponding year.

Results: We observed that HRH availability and quality were focused more in NHPI compared to accessibility and acceptability. Doctors were prioritized over auxiliary nurses-midwives and health assistants. AAAQ indices showed deficits in all dimensions in almost all cadres over the years. The cadres focused by NHPI recommendations did not completely correspond to the deficient cadres.

Conclusion: The framework and indices based method can help identify the gaps between targeted and needed dimensions and cadres for effective HRH strengthening in countries. At the global level, the application of framework and indices will allow a comparison of strengths and weaknesses of HRH-related policies of various nations.

\section{Background}

Human resources for health $(\mathrm{HRH})$ are "all people primarily engaged in actions with the primary intent of enhancing health".(1) HRH is a crucial component of health systems to improve health services coverage and population health outcomes.(2) HRH strengthening is, therefore, quintessential to achieve Universal Health Coverage (UHC)(3) within the broader Sustainable Development Goals (SDGs) framework.(4) However, there is a shortage of 6.9 million and 4.2 million skilled HRH in South-East Asia and Africa, respectively.(5) To address this shortage, under SDG-3.c, the World Health Organization (WHO) encourages nations with an HRH crisis to create and implement national and local policies focused on four HRH dimensions - availability, accessibility, acceptability, and quality (AAAQ).(5)

India is facing a critical shortage of HRH with only 160 skilled health workers per 100,000 people.(6) In $2016,36 \%$ of total HRH served in rural areas which had $71 \%$ population with doctors and nurses constituting the largest portion of $\mathrm{HRH}$.(7) In response to global calls and the existing crisis, India adopted the target of achieving 550 physicians, nurses, and midwives per 100,000 population by 2030 under SDG indicator 3.c.(8) The National Health Policy of India (NHPI), arguably, the most comprehensive policy securing the health of a billion Indians, encompasses recommendations and plans to attain UHC.(9) The first NHPI (1983) was framed as a response to the 1978 Alma Ata Declaration. Subsequently, NHPI was revised in 2002 and 2017 to match the country's needs and progress. Integrating HRH recommendations aimed at AAAQ dimensions in NHPI can bridge national priority-setting and global calls for action.

Analysis of NHPIs in the context of HRH is crucial for the following reasons. First, it helps to study policy changes and their effects on HRH strengthening over an extensive period of three decades. Second, it helps to evaluate the nation's policy commitment towards addressing HRH needs and achieving development targets. Third, it could guide the development of future policies geared towards areas of need in an evidence-based fashion. Thus, our analysis has three main aims:

1. Identify the degree of incorporation of WHO's AAAQ dimensions in NHPI's HRH-related recommendations.

2. Identify dimensional deficiencies in HRH cadres prior to three NHPI adoptions to gauge situational needs and also assess longitudinal trends in deficiencies.

3. Investigate whether NHPI recommendations targeted the deficient HRH dimensions and cadres.

\section{Methods}

\section{Data Sources and Variables:}

We obtained NHPI reports for 1983, 2002, 2017, and the 'Situational Analyses: Backdrop to NHPI 2017' report from the Health Policy section of the National Health Portal of India.(10) We extracted the absolute number of national and rural personnel present for $49 \mathrm{HRH}$ cadres enlisted in Indian Public Health Standards (IPHS),(11) for pre-NHPI years 1982, 2001, and 2016. Data sources and specifications are given in Additional file 1- Table 1. The cadre-wise absolute numbers were converted to HRH personnel density per 100,000 people (P) using population estimates taken from the census tables (Additional file 1Table 1). We calculated two cadre-wise requirement thresholds (R) i.e density of HRH personnel required per 100,000 population using benchmark planning committee reports from Health Survey \& Development or the Bhore Committee (R-1)(12) and High-level Expert Group (HLEG) (R-2).(13) Calculations of P and R values are detailed in Additional File 2. We chose the Bhore Committee (1946) and HLEG (2012) reports as the former presented the first HRH requirement thresholds for Independent India while the latter presented the latest norms. Together they cover the span of over thirty years encompassing the same period covered by NHPIs. The Bhore Committee set an ambitious target for the then India, which would have brought India closer to UHC much earlier. The HLEG presents a recent and realistic target-setting, considering the existing $\mathrm{HRH}$ shortage and global development calls. 
Table 1

Cadre-wise distribution of HRH-related strategies and actions used in the NHPI recommendations fo

\begin{tabular}{|c|c|c|c|c|c|c|c|c|}
\hline \multirow{2}{*}{$\begin{array}{l}\text { NHPI } \\
\text { Year }\end{array}$} & \multicolumn{3}{|l|}{ Availability } & \multicolumn{3}{|c|}{ Accessibility } & \multicolumn{2}{|c|}{ Acceptability } \\
\hline & $\begin{array}{l}\text { Cadre } \\
\text { focused }\end{array}$ & $\begin{array}{l}\text { Recommendations } \\
\text { given }\end{array}$ & $\begin{array}{l}\text { Strategy not } \\
\text { used }\end{array}$ & $\begin{array}{l}\text { Cadre } \\
\text { focused }\end{array}$ & $\begin{array}{l}\text { Recommendations } \\
\text { given }\end{array}$ & Strategy not used & $\begin{array}{l}\text { Cadre } \\
\text { focused }\end{array}$ & $\begin{array}{l}\text { Recommendati } \\
\text { given }\end{array}$ \\
\hline \multirow[t]{13}{*}{1983} & \multirow[t]{3}{*}{ Other ${ }^{\mathrm{a}}$} & \multirow[t]{3}{*}{$\begin{array}{l}\text {-Create new cadre } \\
\text { of sanitary-cum- } \\
\text { epidemiological } \\
\text { staff }\end{array}$} & \multirow{13}{*}{$\begin{array}{l}\text {-Establish } \\
\text { new } \\
\text { training } \\
\text { institutes } \\
\text {-Increase } \\
\text { number of } \\
\text { seats in } \\
\text { existing } \\
\text { training } \\
\text { institutes } \\
\text {-Task } \\
\text { shifting \& } \\
\text { task } \\
\text { sharing }\end{array}$} & \multirow[t]{3}{*}{ Doctors } & \multirow[t]{3}{*}{$\begin{array}{l}\text {-Monetary } \\
\text { incentive by non- } \\
\text { practice allowance }\end{array}$} & $\begin{array}{l}\text {-Establish training } \\
\text { institutes in } \\
\text { underserved areas }\end{array}$ & \multirow{13}{*}{\multicolumn{2}{|c|}{$\begin{array}{l}\text { No recommendation focused c } \\
\text { HRH }\end{array}$}} \\
\hline & & & & & & $\begin{array}{l}\text {-Task shifting \& } \\
\text { multi-tasking of } \\
\text { HRH cadres in } \\
\text { underserved areas }\end{array}$ & & \\
\hline & & & & & & $\begin{array}{l}\text {-Develop } \\
\text { information }\end{array}$ & & \\
\hline & \multirow[t]{10}{*}{$\begin{array}{l}\text { Non-cadre } \\
\text { specific }^{\text {b }}\end{array}$} & \multirow{10}{*}{$\begin{array}{l}\text {-Create norms for } \\
\text { HRH production, } \\
\text {-Measure and } \\
\text { monitor } \\
\text { availability of HRH } \\
\text { using information } \\
\text { systems }\end{array}$} & & \multirow[t]{7}{*}{ AYUSH $^{c}$} & \multirow{7}{*}{$\begin{array}{l}\text {-Mainstream and } \\
\text { integrate } \\
\text { indigenous HRH } \\
\text { cadres } \\
\text {-Task shifting in } \\
\text { underserved areas } \\
\text { by deploying } \\
\text { AYUSH to urban } \\
\text { areas }\end{array}$} & $\begin{array}{l}\text { systems \& tools to } \\
\text { measure \& } \\
\text { monitor }\end{array}$ & & \\
\hline & & & & & & $\begin{array}{l}\text { geographical } \\
\text { distribution of }\end{array}$ & & \\
\hline & & & & & & $\mathrm{HRH}$ & & \\
\hline & & & & & & -Tele-consultation & & \\
\hline & & & & & & $\begin{array}{l}\text {-Mainstream \& } \\
\text { integrate }\end{array}$ & & \\
\hline & & & & & & $\begin{array}{l}\text { indigenous } \mathrm{HRH} \text { in } \\
\text { underserved areas }\end{array}$ & & \\
\hline & & & & & & $\begin{array}{l}\text {-Identify } \\
\text { groups/individuals } \\
\text { motivated to work } \\
\text { in underserved } \\
\text { areas }\end{array}$ & & \\
\hline & & & & \multirow[t]{3}{*}{ Other } & \multirow{3}{*}{$\begin{array}{l}\text {-Create new cadre } \\
\text { of sanitary-cum- } \\
\text { epidemiological } \\
\text { staff specifically } \\
\text { for underserved } \\
\text { areas }\end{array}$} & $\begin{array}{l}\text {-Remove } \\
\text { professional } \\
\text { isolation }\end{array}$ & & \\
\hline & & & & & & $\begin{array}{l}\text {-Remove } \\
\text { administrative } \\
\text { barriers in } \\
\text { recruitment like } \\
\text { walk-in interviews }\end{array}$ & & \\
\hline & & & & & & $\begin{array}{l}\text {-Mandatory rural } \\
\text { postings }\end{array}$ & & \\
\hline \multirow[t]{13}{*}{2002} & \multirow[t]{9}{*}{ Doctors } & $\begin{array}{l}\text {-Introduce minimal } \\
\text { deployment norms }\end{array}$ & \multirow{13}{*}{$\begin{array}{l}\text {-Recruiting } \\
\text { HRH from } \\
\text { foreign } \\
\text { countries } \\
\text {-Retaining } \\
\text { HRH within } \\
\text { country } \\
\text {-Develop } \\
\text { information } \\
\text { systems \& } \\
\text { tools to } \\
\text { measure \& } \\
\text { monitor } \\
\text { availability } \\
\text { of HRH }\end{array}$} & \multirow[t]{11}{*}{ Doctors } & \multirow{6}{*}{$\begin{array}{l}\text {-Mandatory rural } \\
\text { service } \\
\text {-Removing } \\
\text { administrative } \\
\text { barriers of } \\
\text { recruitment } \\
\text {-Task shifting by } \\
\text { AYUSH, LMPs, } \\
\text { medical officers in } \\
\text { underserved areas } \\
\text {-Task sharing with } \\
\text { paramedics }\end{array}$} & $\begin{array}{l}\text {-Establish training } \\
\text { institutes in }\end{array}$ & \multirow[t]{13}{*}{$\begin{array}{l}\text { Non-cadre } \\
\text { specific }\end{array}$} & \multirow{13}{*}{$\begin{array}{l}\text {-Establish staff } \\
\text { norms to meet } \\
\text { specific } \\
\text { requirements o } \\
\text { women }\end{array}$} \\
\hline & & $\begin{array}{l}\text {-Increase no. of } \\
\text { specialist seats in }\end{array}$ & & & & -Incentives for & & \\
\hline & & medical institutes & & & & rural services & & \\
\hline & & $\begin{array}{l}\text {-Establish new } \\
\text { training institutes }\end{array}$ & & & & $\begin{array}{l}\text {-Identification of } \\
\text { groups or }\end{array}$ & & \\
\hline & & $\begin{array}{l}\text {-Task sharing with } \\
\text { paramedics }\end{array}$ & & & & $\begin{array}{l}\text { individuals } \\
\text { motivated towards } \\
\text { serving }\end{array}$ & & \\
\hline & & $\begin{array}{l}\text {-Task shifting by } \\
\text { AYUSH and LMPs }\end{array}$ & & & & $\begin{array}{l}\text {-Removing } \\
\text { professional }\end{array}$ & & \\
\hline & & -Task shifting in & & & -Tele-consultation & isolation & & \\
\hline & & $\begin{array}{l}\text { specialty by allied } \\
\text { professionals }\end{array}$ & & & & $\begin{array}{l}\text {-Develop } \\
\text { information } \\
\text { systems \& tools to }\end{array}$ & & \\
\hline & & $\begin{array}{l}\text {-Task shifting by } \\
\text { medical officers }\end{array}$ & & & & $\begin{array}{l}\text { measure \& } \\
\text { monitor } \\
\text { geographical }\end{array}$ & & \\
\hline & \multirow[t]{2}{*}{ Nurses } & $\begin{array}{l}\text {-Increase no. of } \\
\text { nursing institutes }\end{array}$ & & & & $\begin{array}{l}\text { distribution of } \\
\mathrm{HRH}\end{array}$ & & \\
\hline & & $\begin{array}{l}\text {-Introduce minimal } \\
\text { deployment norms }\end{array}$ & & & & & & \\
\hline & \multirow[t]{2}{*}{ Other } & $\begin{array}{l}\text {-Establish new } \\
\text { training institutes }\end{array}$ & & \multirow[t]{2}{*}{ AYUSH } & \multirow{2}{*}{$\begin{array}{l}\text {-Mainstream \& } \\
\text { integrate } \\
\text { indigenous HRH in } \\
\text { underserved areas }\end{array}$} & & & \\
\hline & & -Create new cadre & & & & & & \\
\hline
\end{tabular}

${ }^{a}$ Other cadres include dentists, mid-level practitioners, community health workers and multi-purpose workers. ${ }^{\mathrm{b}}$ Non-cadre specific recommendations are appli Siddha and Homeopathy, ${ }^{\mathrm{d} L M P s}$ : Licentiate Medical Practitioners, ${ }^{\mathrm{e}} \mathrm{CHWs}$ : Community Health Workers, ${ }^{\mathrm{fIPHS}}$ : Indian Public Health Standards, ${ }^{\mathrm{A} A S H A s: ~ A c c r e ~}$ 


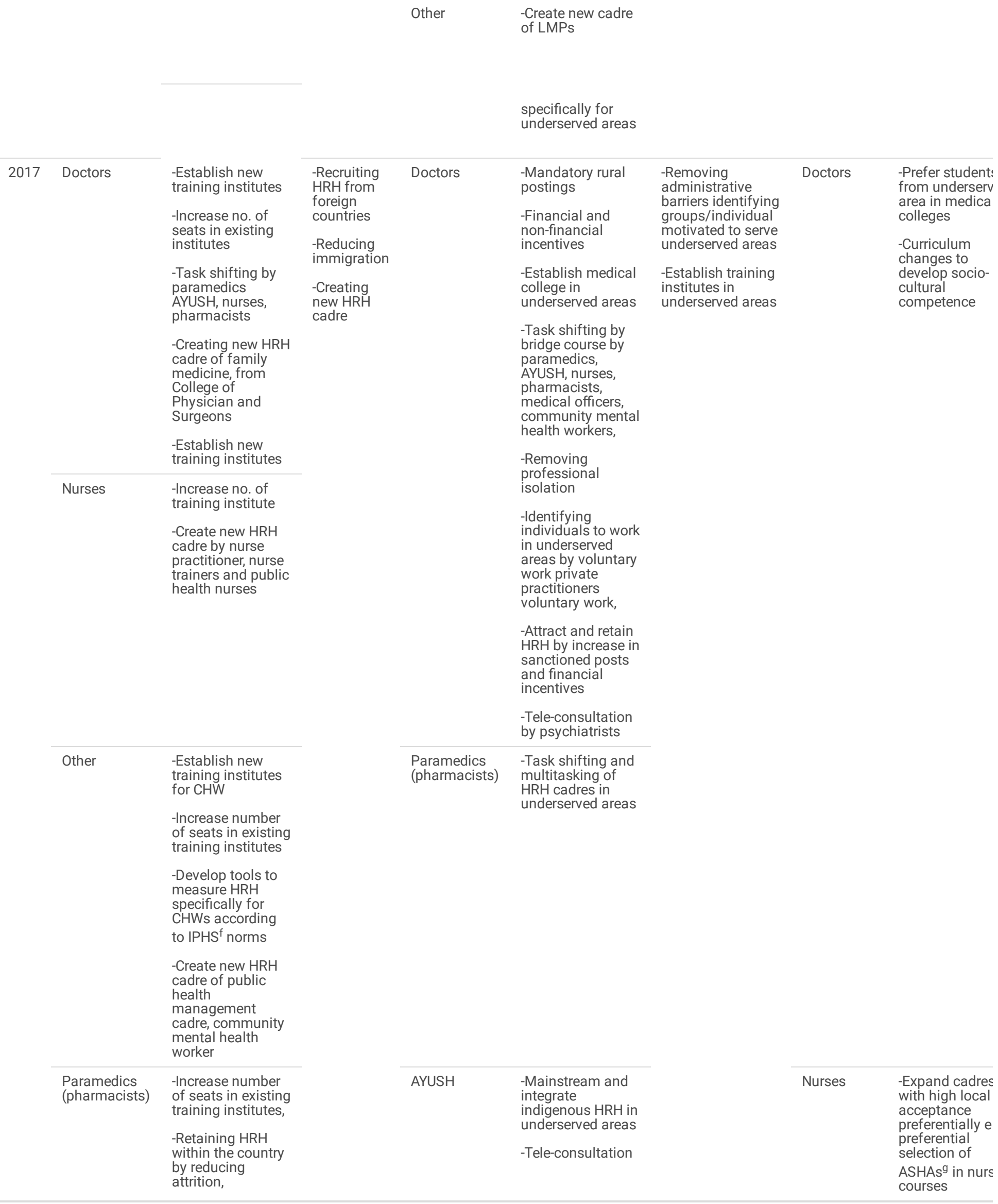

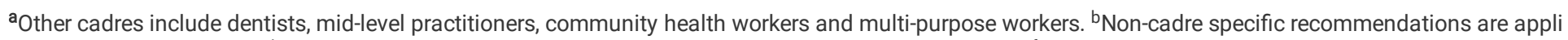
Siddha and Homeopathy, ${ }^{d}$ LMPs: Licentiate Medical Practitioners, ${ }^{e} \mathrm{CHWs}$ : Community Health Workers, $\mathrm{f}$ IPHS: Indian Public Health Standards, gASHAs: Accre 


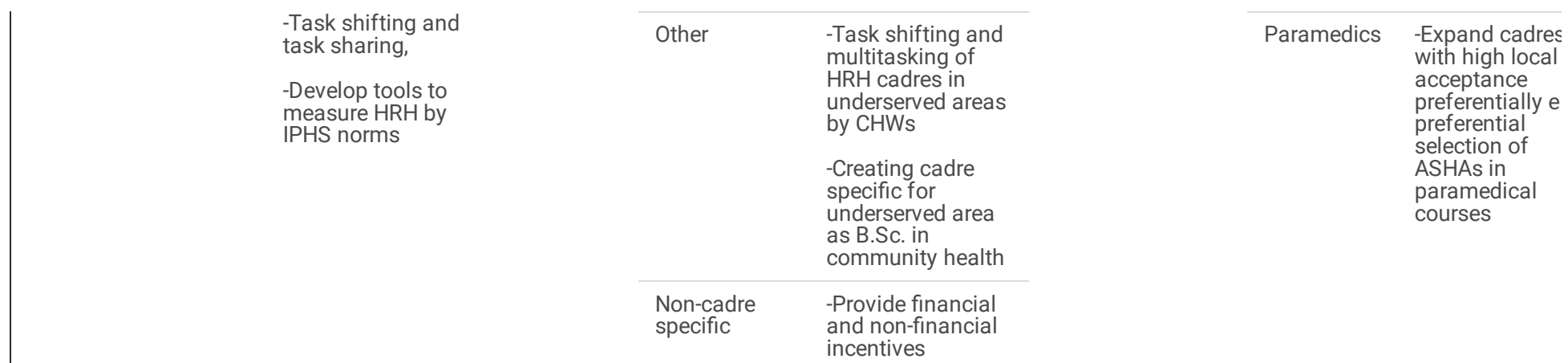

aOther cadres include dentists, mid-level practitioners, community health workers and multi-purpose workers. ${ }^{b}$ Non-cadre specific recommendations are appli Siddha and Homeopathy, ${ }^{d}$ LMPs: Licentiate Medical Practitioners, ${ }^{e} \mathrm{CHWs}$ : Community Health Workers, ${ }^{\mathrm{f} I P H S}$ : Indian Public Health Standards, ${ }^{\mathrm{g}}$ ASHAs: Accre

\section{Framework for Policy Analysis:}

We created a three-tiered framework with dimensions, strategies, and actions for assessing HRH strengthening (Fig. 1). The first level is based on four HRHAAAQ dimensions proposed by the Global Health Workforce Alliance (GHWA)(14) - availability (total number of personnel: stock and production), accessibility (distribution across sectors: public and private, demographics: rural and urban, and levels of care: primary, secondary and tertiary), acceptability (compatibility with the population being served in terms of HRH sex/age composition, skill-mix, cultural awareness, attitudes, and behaviors), and quality (competencies, training and skills, knowledge, and professional work ethics and patients' satisfaction). Based on an iterative scoping review of literature for Indian HRH, we added strategies and actions that could improve each dimension. Strategies are the broad approaches that can be used independently or in combination to improve a dimension. Cutting across dimensions and working in synergy, actions under strategies are directly implementable measures to produce such an improvement. The framework has four dimensions, twenty strategies, and twenty-four actions (Fig. 1).

\section{Indices for Dimensional HRH Deficits}

We formulated four indices that quantified an important strategy corresponding to each AAAQ dimension. Availability deficit (AvD) measures the deficit in the total stock of $\mathrm{HRH}$, accessibility deficit (AsD) measures the maldistribution of rural HRH against their gross national presence, acceptability deficit (ApD) measures the skew in skill-mix, and quality deficit (QD) measures the deficit of qualified HRH.

AvD measures the deficit of present $\mathrm{HRH}$ with respect to the requirement thresholds.

$$
A v D=1-\left(\frac{p}{R}\right)
$$

AsD measures the deficit of $\mathrm{HRH}$ present in rural areas with respect to the national estimates.

$$
A s D=1-\left(\frac{P_{\text {rural }} / R_{\text {rural }}}{P_{\text {national }} / R_{\text {national }}}\right)=1-\left(\frac{P_{\text {rural }}}{R_{\text {national }}}\right) \text {, as } \mathrm{R}_{\text {nural }}=\mathrm{R}_{\text {national }}
$$

$\mathrm{ApD}$ measures the deficit of nursing and supporting cadres with respect to doctors.

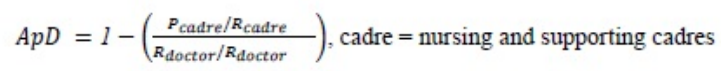

QD measures the deficit of qualified HRH with respect to total estimates i.e. qualified and unqualified. 


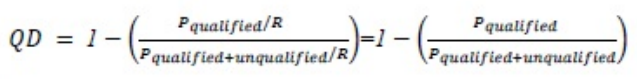

(Eq 4)

These deficit indices (collectively represented as $D$ ) normalized as per contextual pre-determined requirement thresholds $(R)$ indicate $(a)$ no deficit if $D=0$, (b) a positive deficit if $D>0$, and (c) a surplus if $D<0$. Here, we classified HRH deficit quartiles as critical ( 1 to 0.75$)$, high ( 0.74 to 0.50$)$, moderate $(0.49$ to 0.25$)$, and low (0.24 to 0$)$. The surplus was categorized as low $(-0.01$ to -0.24$)$, moderate $(-0.25$ to -0.49$)$, high ( -0.50 to -0.74$)$, and extreme (<-0.75).

\section{Data Analysis:}

\section{Inclusion criteria}

We included only the cadres with $\mathrm{P}$ values available for at least two out of three years at the national level and R prescribed by at least one committee, resulting in eight cadres - auxiliary nurse midwives (ANMs), health assistant females (HAFs), pharmacists, nurses, dentists, indigenous medical practitioners AYUSH (Ayurveda, Yoga, Unani, Siddha, Homeopathy), and doctors (graduates and postgraduates in allopathic medicine). We considered ANMs, HAFs, and nurses together as nursing cadres, while pharmacists and nursing cadres together as supporting cadres.

\section{Analysis 1}

To evaluate the incorporation of AAAQ dimensions and focussed cadres, we screened all NHPI sections for HRH-related recommendations. Each recommendation was coded according to - addressed dimensions, targeted cadres, recommended strategies, and employed actions (Additional file 1- Table 2). Recommendations not specific to any cadres were coded as 'non-cadre specific'. Cadres apart from the eight mentioned above were grouped as 'others'. For each NHPI, we recorded the total number of dimension-wise and cadre-wise recommendations independently and further cross-tabulated them. Variations in the total number of mentions across NHPIs were used to determine trends in changing focus. The focus was determined by the number of mentions.

Table 2

Number of cadre-wise recommendations of HRH in the NHPIs for AAAQ dimensions.

\begin{tabular}{|c|c|c|c|c|c|c|c|c|c|c|c|c|}
\hline \multirow[t]{3}{*}{ Cadres } & \multicolumn{12}{|c|}{ Dimension-Wise Recommendations } \\
\hline & \multicolumn{3}{|c|}{ Availability } & \multicolumn{3}{|c|}{ Accessibility } & \multicolumn{3}{|c|}{ Acceptability } & \multicolumn{3}{|c|}{ Quality } \\
\hline & 1983 & 2002 & 2017 & 1983 & 2002 & 2017 & 1983 & 2002 & 2017 & 1983 & 2002 & 2017 \\
\hline Doctors & 0 & 6 & 12 & 1 & 4 & 12 & 0 & 0 & 0 & 0 & 4 & 14 \\
\hline Nurses & 0 & 4 & 2 & 0 & 1 & 2 & 0 & 0 & 1 & 0 & 1 & 6 \\
\hline AYUSH $^{a}$ & 0 & 0 & 0 & 1 & 0 & 4 & 0 & 0 & 1 & 0 & 0 & 1 \\
\hline $\mathrm{ANMs}^{\mathrm{b}}$ & 0 & 0 & 0 & 0 & 0 & 0 & 0 & 0 & 0 & 0 & 0 & 0 \\
\hline$H A F s^{c}$ & 0 & 0 & 0 & 0 & 0 & 0 & 0 & 0 & 0 & 0 & 0 & 0 \\
\hline Dentists & 0 & 1 & 0 & 0 & 0 & 0 & 0 & 0 & 0 & 0 & 0 & 1 \\
\hline Pharmacists & 0 & 0 & 4 & 0 & 1 & 1 & 0 & 0 & 0 & 0 & 2 & 4 \\
\hline Others $^{d}$ & 1 & 1 & 7 & 0 & 1 & 6 & 0 & 0 & 2 & 2 & 0 & 2 \\
\hline Non- cadre specific ${ }^{e}$ & 2 & 0 & 1 & 1 & 1 & 1 & 0 & 2 & 0 & 4 & 1 & 6 \\
\hline Total recommendations & 3 & 12 & 26 & 3 & 8 & 26 & 0 & 2 & 4 & 6 & 8 & 34 \\
\hline
\end{tabular}

\section{Analysis 2}

We calculated AAAQ deficit indices for eight cadres using R-1 and R-2 for pre-NHPI years at national (total) and rural levels. P values were unavailable for 1982 rural $\mathrm{HRH}$. Hence, six sets of national and four sets of rural AvD and ApD and two sets of AsD were obtained. Similarly, two sets of QD were calculated as the qualification status of HRH was unavailable for 1982. (a) We looked at the longitudinal changes in cadre-wise national and rural deficits from 1982 to 2016 using both R-1 and R-2. (b) For situational analyses, we used cadre-wise national-level deficit indices calculated using 'P' values for each pre-NHPI year (1982, 2001, and 2016) and relevant 'R' values i.e. R-1 for 1983-NHPI and 2002-NHPI, R-2 for 2017-NHPI. Cadres were classified into corresponding deficit or surplus categories. 


\section{Analysis 3}

To check whether NHPI recommendations targeted the deficient HRH dimensions and cadres, we compared focused cadres for each dimension in each NHPI with their deficit categories for corresponding years. We used (a) cadre-wise recommendations corresponding to each dimension from Analysis 1 (b) cadrewise deficit categories under each dimension taken from Analysis 2.b. We arranged the cadres in descending order according to the number of NHPIrecommendations. We then compared whether or not the focused cadres in NHPI corresponded with their deficit categories i.e. whether cadres with high deficit had more focus in the NHPI recommendations and vice versa.

\section{Results}

\section{Dimension-wise and cadre-wise distribution of NHPI recommendations}

The total HRH-related recommendations increased from twelve in 1983, thirty in 2002 to ninety in 2017. Figure 2A shows the distribution of recommendations across AAAQ dimensions. Across the years, the dimensional focus shifted from HRH quality to availability and back to quality. Focus on accessibility increased while acceptability was consistently neglected. The commonly proposed strategies for improving availability, accessibility, and quality were: establishing new and expanding existing training institutes, task shifting/sharing, and need-based changes in training, respectively (Table 1). The total cadrespecific recommendations increased from five in 1983, twenty-six in 2002 to eighty-two in 2017 (Fig. 2B) with seven, four, and eight non-cadre specific recommendations, respectively. Doctors were prioritized across all NHPIs while ANMs and HAFs were neglected. The commonly proposed implementation strategies for doctors were mandatory rural service and changes in the curriculum. Improvement in training, integrating AYUSH in underserved areas, and establishing professional councils were common strategies for nurses, AYUSH practitioners, and paramedics, respectively (Table 1). Cross-tabulation of cadrewise and dimension-wise number of recommendations is given in Table 2.

\section{2.a. Longitudinal trends of the dimension-wise deficits over three decades}

Over three decades, national AvD showed a decreasing trend for all cadres under both norms. The steepest decrease indicated as percentage drop was seen for pharmacists (150\%) and doctors (766\%) using Bhore (Fig. 3A) and HLEG norms (Fig. 3B), respectively. Least fall was in HAFs under both norms (30\% Bhore and 26\% - HLEG). Majority cadres showed little change in rural AvD. ANMs (16\%) and AYUSH (248\%) showed the greatest fall in rural AvD using Bhore and HLEG norms (Figs. 3C and 3D), respectively. AsD for nurses, pharmacists, and doctors was almost constant ( 1\% change) between 2001 and 2016 while AsD increased for remaining cadres (Fig. 4). ApD showed a decreasing trend under both requirement thresholds at national (Figs. 5A and 5B) and rural levels (Figs. 5C and 5D). QD for all cadres declined with the fall being steepest for dentists (621\%) and least for pharmacists (47\%) (Fig. 6).

\section{2.b. Retrospective situational analyses of HRH for pre-NHPI years}

In 1982, all cadres had critical-to-high AvD with the greatest deficit for nurses using R-1 as norm (Fig. 3A). High and moderate ApDs were noted for nursing and supporting cadres, respectively (Fig. 5A). AsD and QD were not measured due to a lack of data. In 2001, all cadres except pharmacists had positive AvDs with nurses being the most deficient (Fig. 3A). All cadres showed poor accessibility with AsD being greatest for nurses and least for HAFs (Fig. 4). For all cadres, unqualified HRH was more than the qualified indicating deficit in quality with QD being highest for pharmacists and lowest for AYUSH (Fig. 6). Moderate and low ApDs were noted for $\mathrm{HRH}$, considering nursing and supporting cadres, respectively (Fig. 5A). In 2016, using R-2, all cadres except ANMs and HAFs had surplus availability (Fig. 3B). All cadres showed accessibility deficits with AsD categories almost identical to that in 2001 (Fig. 4). QD was highest for pharmacists and lowest for dentists (Fig. 6). Nursing and supporting cadres showed high and moderate ApDs, respectively (Fig. 5B).

\section{Comparison of cadre-wise deficit categories with cadre focused in NHPIs}

Table 3 shows that no cadre-specific recommendations were made under AAAQ-dimensions in NHPI-1983 while majority cadres had moderate-to-critical deficits. In 2002, no availability-related recommendations were made for HAFs and ANMs which had high and moderate AvDs. Pharmacists and nurses with critical AsD had only one accessibility-related recommendation each, and AYUSH, dentists, and ANMs with moderate-to-high deficits had none. Pharmacists and nurses with critical QDs had only two and one quality-related recommendations respectively, and AYUSH and dentists with high to moderate deficits had none. In 2017, there were twelve availability-related recommendations for doctors who had extreme surplus while HAFs and ANMs with high to low availability deficits had no recommendations. Nurses and pharmacists with critical AsD had two and one recommendations, respectively while dentists, ANMs, and HAFs with critical to high deficits had none. Doctors had fourteen quality-related recommendations despite showing a low deficit. In all NHPIs, negligible acceptability-related recommendations were made despite consistent deficits. 
Table 3

Number of cadre-wise recommendations compared with their deficit categories for AAAQ dimensions.

\begin{tabular}{|c|c|c|c|c|c|c|c|c|}
\hline & 1983 & & & 2002 & & & 2017 & \\
\hline Dimension & Cadre & Recommendations & $\begin{array}{l}\text { Deficit } \\
\text { category } \\
\text { using } \\
\text { Bhore } \\
\text { threshold }\end{array}$ & Cadre & Recommendations & $\begin{array}{l}\text { Deficit } \\
\text { category } \\
\text { using } \\
\text { Bhore } \\
\text { threshold }\end{array}$ & Cadre & Recommendations \\
\hline \multirow[t]{7}{*}{ Availability } & $\mathrm{ANMs}^{\mathrm{a}}$ & $0 / 3$ & $\begin{array}{l}\text { critical } \\
\text { deficit }\end{array}$ & Doctors & $6 / 12$ & $\begin{array}{l}\text { high } \\
\text { deficit }\end{array}$ & Doctors & $12 / 26$ \\
\hline & $\mathrm{HAFs}^{\mathrm{b}}$ & $0 / 3$ & $\begin{array}{l}\text { critical } \\
\text { deficit }\end{array}$ & Nurses & $4 / 12$ & $\begin{array}{l}\text { critical } \\
\text { deficit }\end{array}$ & Pharmacists & $4 / 26$ \\
\hline & Nurses & $0 / 3$ & $\begin{array}{l}\text { critical } \\
\text { deficit }\end{array}$ & AYUSH & $1 / 12$ & - & Nurses & $2 / 26$ \\
\hline & Pharmacists & $0 / 3$ & $\begin{array}{l}\text { high } \\
\text { deficit }\end{array}$ & HAFs & $0 / 12$ & $\begin{array}{l}\text { high } \\
\text { deficit }\end{array}$ & HAFs & $0 / 26$ \\
\hline & AYUSH ${ }^{c}$ & $0 / 3$ & - & ANMs & $0 / 12$ & $\begin{array}{l}\text { moderate } \\
\text { deficit }\end{array}$ & ANMs & $0 / 26$ \\
\hline & Dentists & $0 / 3$ & - & Dentists & $0 / 12$ & - & Dentists & $0 / 26$ \\
\hline & Doctors & $0 / 3$ & $\begin{array}{l}\text { high } \\
\text { deficit }\end{array}$ & Pharmacists & $0 / 12$ & $\begin{array}{l}\text { low } \\
\text { surplus }\end{array}$ & AYUSH & $0 / 26$ \\
\hline \multirow[t]{7}{*}{ Accessibility } & ANMs & - & - & Doctors & $4 / 8$ & $\begin{array}{l}\text { critical } \\
\text { deficit }\end{array}$ & Doctors & $12 / 26$ \\
\hline & HAFs & - & - & Nurses & $1 / 8$ & $\begin{array}{l}\text { critical } \\
\text { deficit }\end{array}$ & AYUSH & $4 / 26$ \\
\hline & Nurses & - & - & Pharmacists & $1 / 8$ & $\begin{array}{l}\text { critical } \\
\text { deficit }\end{array}$ & Nurses & $2 / 26$ \\
\hline & Pharmacists & - & - & ANMs & $0 / 8$ & $\begin{array}{l}\text { high } \\
\text { deficit }\end{array}$ & Pharmacists & $1 / 26$ \\
\hline & AYUSH & - & - & Dentists & $0 / 8$ & $\begin{array}{l}\text { high } \\
\text { deficit }\end{array}$ & Dentists & $0 / 26$ \\
\hline & Dentists & - & - & AYUSH & $0 / 8$ & $\begin{array}{l}\text { moderate } \\
\text { deficit }\end{array}$ & ANMs & $0 / 26$ \\
\hline & Doctors & - & - & HAFs & $0 / 8$ & $\begin{array}{l}\text { low } \\
\text { deficit }\end{array}$ & HAFs & $0 / 26$ \\
\hline \multirow[t]{2}{*}{ Acceptability } & $\begin{array}{l}\text { Nursing } \\
\text { cadres }\end{array}$ & $0 / 0$ & $\begin{array}{l}\text { high } \\
\text { deficit }\end{array}$ & $\begin{array}{l}\text { Nursing } \\
\text { cadres }\end{array}$ & $0 / 2$ & $\begin{array}{l}\text { moderate } \\
\text { deficit }\end{array}$ & $\begin{array}{l}\text { Nursing } \\
\text { cadres }\end{array}$ & $1 / 4$ \\
\hline & $\begin{array}{l}\text { Supporting } \\
\text { cadres }\end{array}$ & $0 / 0$ & $\begin{array}{l}\text { high } \\
\text { deficit }\end{array}$ & $\begin{array}{l}\text { Supporting } \\
\text { cadres }\end{array}$ & $0 / 2$ & $\begin{array}{l}\text { low } \\
\text { deficit }\end{array}$ & $\begin{array}{l}\text { Supporting } \\
\text { cadres }\end{array}$ & $1 / 4$ \\
\hline \multirow[t]{7}{*}{ Quality } & ANMs & - & - & Doctors & $4 / 8$ & $\begin{array}{l}\text { high } \\
\text { deficit }\end{array}$ & Doctors & $13 / 34$ \\
\hline & HAFs & - & - & HAFs & $4 / 8$ & - & Nurses & $6 / 34$ \\
\hline & Nurses & - & - & Pharmacists & $2 / 8$ & $\begin{array}{l}\text { critical } \\
\text { deficit }\end{array}$ & Pharmacists & $4 / 34$ \\
\hline & Pharmacists & - & - & Nurses & $1 / 8$ & $\begin{array}{l}\text { critical } \\
\text { deficit }\end{array}$ & AYUSH & $1 / 34$ \\
\hline & AYUSH & - & - & Dentists & $0 / 8$ & $\begin{array}{l}\text { high } \\
\text { deficit }\end{array}$ & Dentists & $1 / 34$ \\
\hline & Dentists & - & - & AYUSH & $0 / 8$ & $\begin{array}{l}\text { moderate } \\
\text { deficit }\end{array}$ & ANMs & $0 / 34$ \\
\hline & Doctors & - & - & ANMs & $0 / 8$ & - & HAFs & $0 / 34$ \\
\hline
\end{tabular}

'- indicates uncalculated deficits due to unavailable data. AvD of AYUSH and dentists for 1982 and 2001, AsD of all cadres for 1982, QD of all cadres for 198 ANMs and HAFs for 2001 and 2016 were not calculated due to unavailability of data. HRH deficit quartiles were classified as - critical (1 to 0.75$)$, high (0.74 tı moderate $(0.49$ to 0.25$)$, and low $(0.24$ to 0$)$. The surplus was categorized as low $(-0.01$ to -0.24$)$, moderate $(-0.25$ to -0.49$)$, high $(-0.50$ to -0.74$)$, and extreme ${ }^{a} A N M s:$ Auxiliary Nurse-Midwives, ${ }^{b}$ HAFs: Health Assistants Female, ${ }^{c}$ AYUSH: Ayurveda, Yoga and Naturopathy, Unani, Siddha and Homeopathy. 


\section{Discussion}

Our results showcase that NHPIs' HRH-related recommendations were not structured to incorporate AAAQ dimensions. Over three decades, the main focus has been on HRH availability and quality, with reduced attention to accessibility and acceptability. Recommendations consistently seem to prioritize doctors over other cadres like ANMs and HAFs. The situational analysis revealed dimension-wise deficits in most cadres for all three NHPIs. Longitudinally, the magnitude of deficits declined for all dimensions except accessibility. NHPIs did not always focus on the deficient cadres thus failing to fully address the situational HRH deficiencies.

The 2014 GHWA report indicated that there was 'insufficient data' for reliance on India's HRH policy on the AAAQ dimensions(14). We evaluated the HRHrelated recommendations of NHPIs for the incorporation of AAAQ dimensions to fill this gap. Deficiencies in HRH dimensions have been previously identified for India as shortages in HRH availability(15), skewed urban-rural distribution depicting disparities in accessibility(15), poor quality indicated by a substantial proportion of unregistered/unqualified $\mathrm{HRH}(15)$, and low nurse-to-physician ratios compromising workforce acceptability(14). While policies focusing on increasing $\mathrm{HRH}$ production have had success in enhancing availability, they have failed to improve the accessibility and quality of the workforce(16). Moreover, acceptability and regulation of outsized unqualified $\mathrm{HRH}$ remain completely unaddressed $(14,17)$.

Previously, HRH availability and accessibility in India (7) and other countries have been measured cross-sectionally(18) and longitudinally(19, 20), using density as a metric. Here, we formulated normalized cadre-wise AAAQ deficit indices for HRH that can bridge research and policymaking. The advantage of indices over density is that they are indicative of surplus or deficit with respect to contextual requirement norms (thresholds) determined by factors such as health financing, workforce efficiency, etc. In other studies, HRH-related policies have been assessed through interview methods(20), process tracing(18), or qualitative summarization(21). Our framework-based policy analysis is systematic and allows evaluation against quantitative indices. It can be used to study the progress of the National Health Mission (India) and translated to evaluate the HRH policies of other countries. The framework focuses on standardized policy analysis removing stakeholder bias seen in interviews and the investigator's bias in qualitative summaries. The conjoint application of framework and indices generates information useful for rigorous process-tracing.

Focusing on all four dimensions is crucial because population health outcomes can improve only when the high-quality HRH is available where needed in the form acceptable to the people(22). Integrating AAAQ dimensions in HRH parts of the health policies have shown to increase HRH density and improve population health outcomes(18). Adopting and locally implementing policies that address these dimensions is crucial and demands several prerequisites - a) identification of deficiencies in cadres through dimension-wise indices(19,20), b) identification of dimension-wise and cadre-wise focus of HRH policies using a predetermined framework $(21,23), c)$ assessing the mismatches between dimensional deficiencies of HRH and focus of policy, d) experimentation with and evaluation of strategies and actions for their relevance, effectiveness, and cost-effectiveness(16, 24). Application of integrated indices-framework approach will allow cross-national comparison of strengths and weaknesses of $\mathrm{HRH}$ policies with respect to contextual needs and generate evidence for strategies and actions instrumental for dimension-wise HRH improvements.

In India, policies should be restructured to incorporate strategies addressing AAAQ dimensions for HRH strengthening. This will allow for an evidence-based, coordinated, and sustained response towards the HRH crisis. Indicators for HRH acceptability should be to be defined in the Indian context and actively integrated into policies. Cadre-specific recommendations should focus on primary-care level cadres like ANMs, HAFs, community health workers, and rural physicians. Implementation of strategies like reducing attrition in $\mathrm{HRH}$, removing administrative barriers for deployment, developing socio-cultural competence, and regular assessment of in-service staff is crucial. Robust efforts to continually develop and check HRH requirement thresholds are necessary to address the relevance of AAAQ indices. There is an urgent need for a dedicated national HRH policy that measures needs, and develops, executes, and monitors plans to enhance AAAQ of HRH in India.

Our study has several limitations. First, the P values for 1982 are calculated using data from different sources (Additional File 1-Table 1) demanding caution for interpretation of the results. Second, 1982 rural AvD, rural ApD, AsD, and QD were not calculated due to a lack of cadre-wise rural HRH data for the preceding year. However, following the longitudinal declining trend of the deficit, we can infer that the above-mentioned deficits must be higher than those in 2001 and 2016 for all dimensions. Third, focused dimensions and cadres in NHPIs were determined using the number of mentions. There are other ways to determine focus such as measuring relevance, effectiveness, and cost-effectiveness of the recommended strategy(24). However, such data is not for LMICs, and measuring the strength of strategies/actions was out of the scope of study(24)].

\section{Conclusions}

The framework and indices based method can help identify the gaps between targeted and needed dimensions and cadres for effective HRH strengthening in countries. At the global level, the application of framework and indices will allow a comparison of the strengths and weaknesses of HRH-related policies and indicate implementation strategies and actions.

\section{List Of Abbreviations}

$\mathrm{HRH}$ : Human Resources for Health

AAAQ: Availability, Accessibility, Acceptability, and Quality

NHPI: National Health Policy of India

UHC: Universal Health Care 
HLEG: High-level Expert Group

P: HRH personnel density per 100,000 people

R: density of $\mathrm{HRH}$ personnel required per 100,000 population

R-1: density of HRH personnel required per 100,000 population according to Bhore Committee thresholds

R-2: density of HRH personnel required per 100,000 population according to HLEG thresholds

GHWA: Global Health Workforce Alliance

AvD: Availability Deficit

AsD: Accessibility Deficit

ApD: Acceptability Deficit

QD: Quality Deficit

ANMs: Auxiliary Nurse Midwives

HAFs: Health Assistants Female

AYUSH: Ayurveda, Yoga, Unani, Siddha, Homeopathy

LMICs: Lower-Middle income countries

CHW: Community Health Worker

LMP: Licentiate Medical Practitioner

ASHA: Accredited Social Health Activist

IPHS: Indian Public Health Standards

\section{Declarations}

Ethics approval and consent to participate: Not applicable

Consent for publication: Not applicable

Availability of data and materials: The datasets supporting the conclusions of this article are included with the article and its additional files.

Competing interests: The authors declare no competing interests.

Funding: The study did not have any primary research funder or sponsor. During the time of the study, SZ was supported by Duke Global Health Institute Merit Scholarship and Assistantship; SD was employed as Medical House Officer, Government Medical College, and Hospital, Nagpur, India.

Authors' contributions: SD and SZ had access to all the data and take responsibility for its integrity and accuracy of the analysis.

Study concept and design: SD and SZ

Acquisition, analysis, or interpretation of data: All authors

Drafting of the manuscript: All authors

Literature review: SD and JV

Critical revision of the manuscript for important intellectual content: All authors.

Statistical analysis: SD and JV

Obtained study funding: Not Applicable

Administrative, technical, or material support: SZ

Study supervision: SZ

Acknowledgments: We would like to acknowledge Pushkar Nimkar for retrieving 1983 present HRH data from the National Sample Survey Office (NSSO) and Nanditha Venkatesan, Lokesh Krishna, and Rachit Sekhrajka for their inputs on the manuscript. 


\section{References}

1. Guilbert J-J. The World Health Report 2006: working together for health. Educ Health [Internet]. 2006 Nov; 19(3):385-7. Available from: http://dx.doi.org/10.1080/13576280600937911

2. Speybroeck N, Kinfu Y, Dal Poz MR, Evans DB. Reassessing the relationship between human resources for health, intervention coverage and health outcomes. Available from: https://www.who.int/hrh/documents/reassessing_relationship.pdf

3. Human resources for health [Internet]. [cited 2020 Aug 8]. Available from: https://www.undp-capacitydevelopmenthealth.org/en/capacities/focus/programme-management/human-resources/

4. Organization WH, Others. Framing the health workforce agenda for the Sustainable Development Goals: biennium report 2016-2017: WHO health workforce [Internet]. World Health Organization; 2017. Available from: https://apps.who.int/iris/bitstream/handle/10665/272600/WHO-HIS-HWFbienniumreport-2017.1-eng.pdf

5. WHO | Global strategy on human resources for health: Workforce 2030. 2017 Sep 29 [cited 2020 Aug 8]; Available from: https://www.who.int/hrh/resources/pub_globstrathrh-2030/en/

6. Skilled health workforce in India does not meet WHO recommended threshold [Internet]. [cited 2020 Aug 8]. Available from: https://www.bmj.com/company/newsroom/skilled-health-workforce-in-india-does-not-meet-who-recommended-threshold/

7. Karan A, Negandhi H, Nair R, Sharma A, Tiwari R, Zodpey S. Size, composition and distribution of human resource for health in India: new estimates using National Sample Survey and Registry data. BMJ Open [Internet]. 2019 May 27;9(4):e025979. Available from: http://dx.doi.org/10.1136/bmjopen-2018025979

8. SDG-India-Index-2.0_27-Dec.pdf. Available from: https://niti.gov.in/sites/default/files/2019-12/SDG-India-Index-2.0_27-Dec.pdf

9. national_health_policy_2017.pdf [Internet]. Available from: https://www.nhp.gov.in/nhpfiles/national_health_policy_2017.pdf

10. National Health Portal of India, Gateway to Authentic Health Information [Internet]. [cited 2020 Aug 8]. Available from: https://www.nhp.gov.in/

11. Ministry of Health \&, Family Welfare-Government of India. Indian Public Health Standards [Internet]. [cited 2020 Aug 8]. Available from: https://nhm.gov.in/index1.php?lang=1\&level=2\&sublinkid=971\&lid=154

12. Bhore SJ. Report of the Health Survey and Development Committee Volume 3 Appendix 2 [Internet]. 1945. Available from: https://www.nhp.gov.in/sites/default/files/pdf/Bhore_Committee_Report-3.pdf

13. Planning Commission of India. High Level Expert Group on Universal Health Coverage of India [Internet]. 2011 Nov. Available from: https://nhm.gov.in/images/pdf/publication/Planning_Commission/rep_uhc0812.pdf

14. Global Health Workforce Alliance (GHWA) Secretariat and the World Health Organization (WHO). No Health without Workforce. 2014; Available from: https://www.who.int/workforcealliance/knowledge/resources/GHWA-a_universal_truth_report.pdf?ua=1

15. Rao KD, Shahrawat R, Bhatnagar A. Composition and distribution of the health workforce in India: estimates based on data from the National Sample Survey. WHO South East Asia J Public Health [Internet]. 2016 Sep;5(2):133-40. Available from: http://dx.doi.org/10.4103/2224-3151.206250

16. Hazarika I. Health workforce in India: assessment of availability, production and distribution. WHO South East Asia J Public Health [Internet]. 2013 Apr;2(2):106-12. Available from: http://dx.doi.org/10.4103/2224-3151.122944

17. Chandra S. Indian healthcare's inconvenient truth. Business Line [Internet]. 2017 Nov 30 [cited 2020 Aug 15]; Available from: https://www.thehindubusinessline.com/opinion/indian-healthcares-inconvenient-truth/article22259516.ece

18. WHO | Human resources for health and universal health coverage: fostering equity and effective coverage. 2017 May 10 [cited 2020 Aug 9 ]; Available from: https://www.who.int/bulletin/volumes/91/11/13-118729/en/

19. Pozo-Martin F, Nove A, Lopes SC, Campbell J, Buchan J, Dussault G, et al. Health workforce metrics pre- and post-2015: a stimulus to public policy and planning. Hum Resour Health [Internet]. 2017 Feb 15;15(1):14. Available from: http://dx.doi.org/10.1186/s12960-017-0190-7

20. Craveiro I, Hortale V, Oliveira APC de, Dal Poz M, Portela G, Dussault G. The utilization of research evidence in Health Workforce Policies: the perspectives of Portuguese and Brazilian National Policy-Makers. J Public Health [Internet]. 2018 Mar 1;40(suppl_1):i50-6. Available from: http://dx.doi.org/10.1093/pubmed/fdx148

21. Hamdan M, Defever M. Human resources for health in Palestine: a policy analysis. Part I: Current situation and recent developments. Health Policy [Internet]. 2003 May;64(2):243-59. Available from: http://dx.doi.org/10.1016/s0168-8510(03)00004-6

22. WHO | What do we mean by availability, accessibility, acceptability and quality (AAAQ) of the health workforce? 2014 Jan 13 [cited 2020 Aug 9]; Available from: https://www.who.int/workforcealliance/media/qa/04/en/

23. van de Pas R, Veenstra A, Gulati D, Van Damme W, Cometto G. Tracing the policy implementation of commitments made by national governments and other entities at the Third Global Forum on Human Resources for Health. BMJ Glob Health [Internet]. 2017 Oct 25;2(4):e000456. Available from: http://dx.doi.org/10.1136/bmjgh-2017-000456

24. WHO | Increasing access to health workers in remote and rural areas through improved retention. 2014 Oct 3 [cited 2020 Aug 9]; Available from:

\section{Figures}




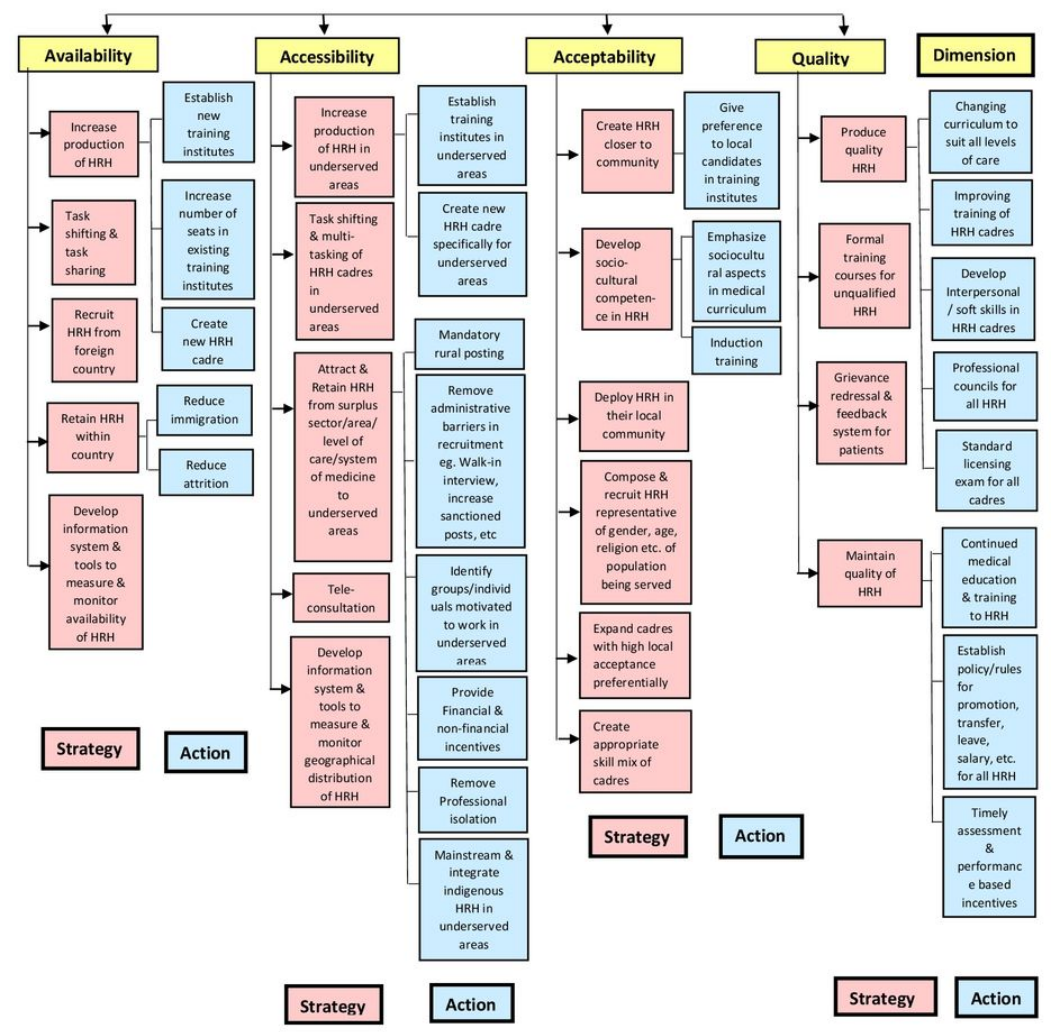

\section{Figure 1}

Strategies and actions for HRH strengthening for availability, accessibility, acceptability, and quality dimensions. Legend - HRH: Human Resources for Health. 
$2 \mathrm{~A}$.
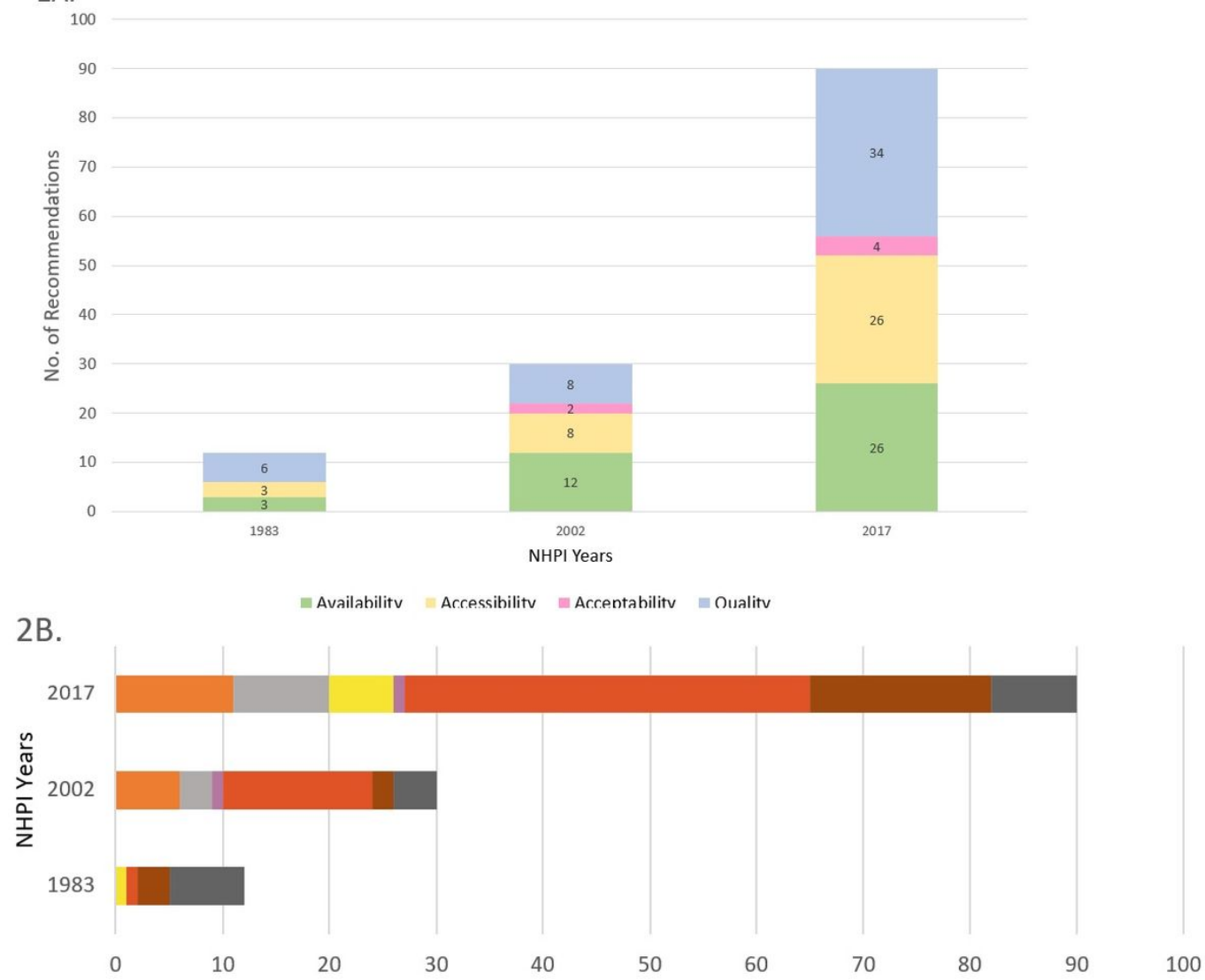

No. of Recommendations

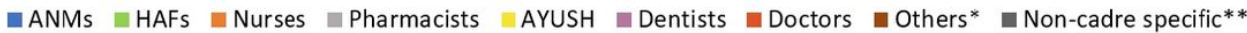

\section{Figure 2}

A: Dimension-wise distribution of HRH-related recommendations of NHPI. Legend - Numbers written inside the bars denote the number of recommendations. NHPI: National Health Policy of India. B: Cadre-wise distribution of HRH-related recommendations of NHPI 1983, 2002, 2017. Legend - *0thers include dentists, mid-level practitioners and multi-purpose workers. ${ }^{*}$ Non-cadre specific recommendations are applicable to all HRH cadres. NHPI: National Health Policy of India, HRH: Human resources for Health, AYUSH: Ayurveda, Yoga and Naturopathy, Unani, Siddha and Homeopathy, ANMs: Auxiliary Nurse-Midwives, HAFs: Health Assistants Female. 
$3 A$.

Bhore (R-1)

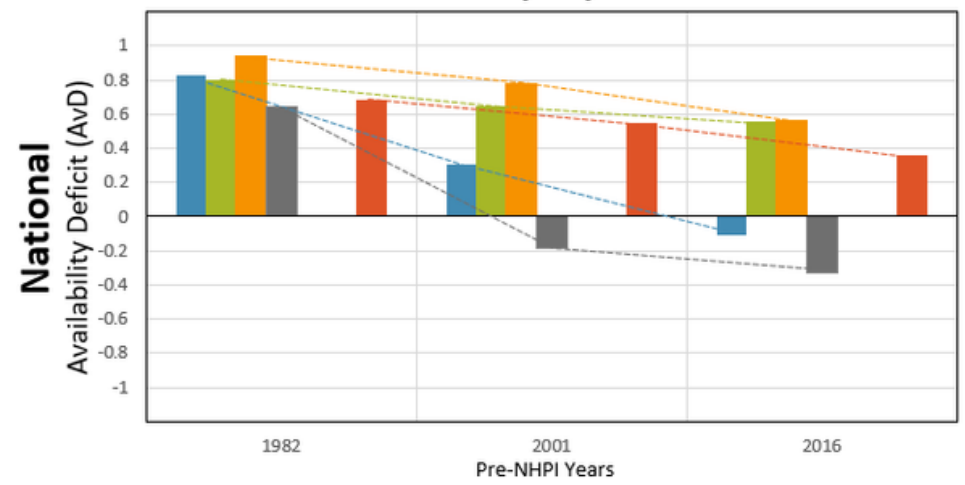

3C.

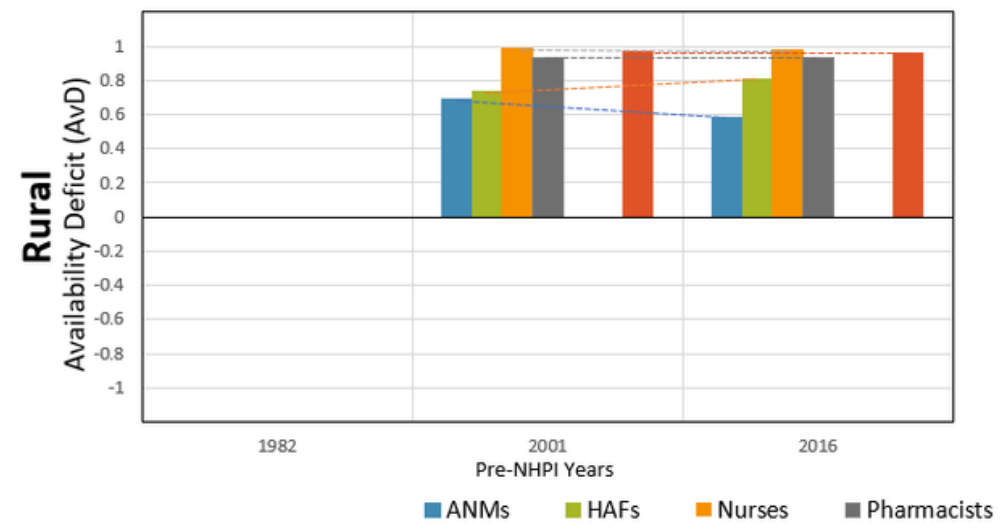

$3 B$.

HLEG (R-2)

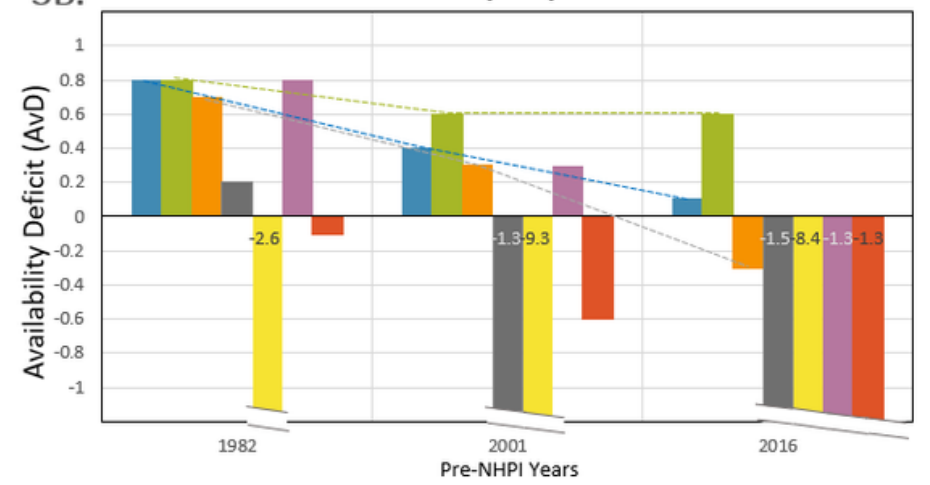

3D.

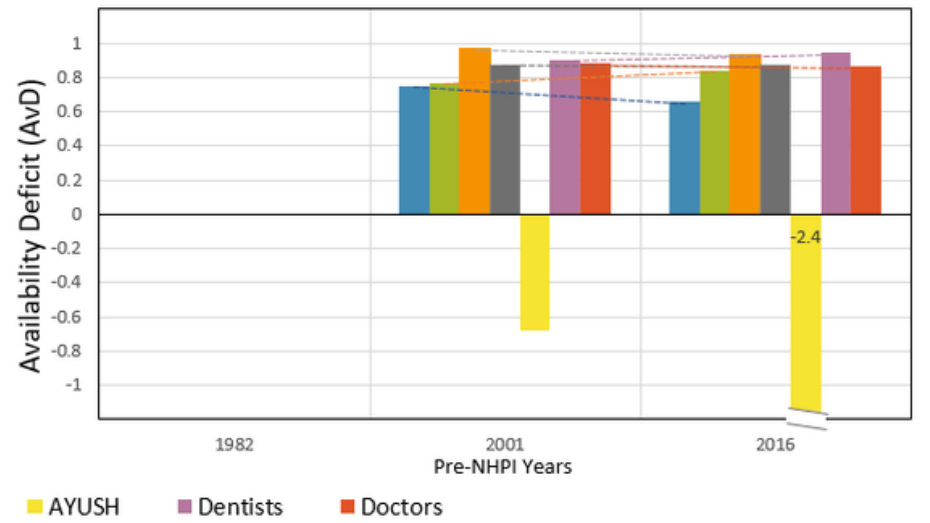

Figure 3

Availability Deficit (AvD) for pre-NHPI years 1982, 2001, 2016 according to Bhore and HLEG norms. Legend - Dashed lines indicate the longitudinal changes in deficit. Truncated bars indicate that the deficit was less than -1 and the corresponding values are written on the bars. Availability Deficit of AYUSH and dentists for 1983 and 2002 were not calculated due to unavailable requirement thresholds. NHPI: National Health Policy of India, AYUSH: Ayurveda, Yoga and Naturopathy, Unani, Siddha and Homeopathy, ANMs: Auxiliary Nurse-Midwives, HAFs: Health Assistants Female.

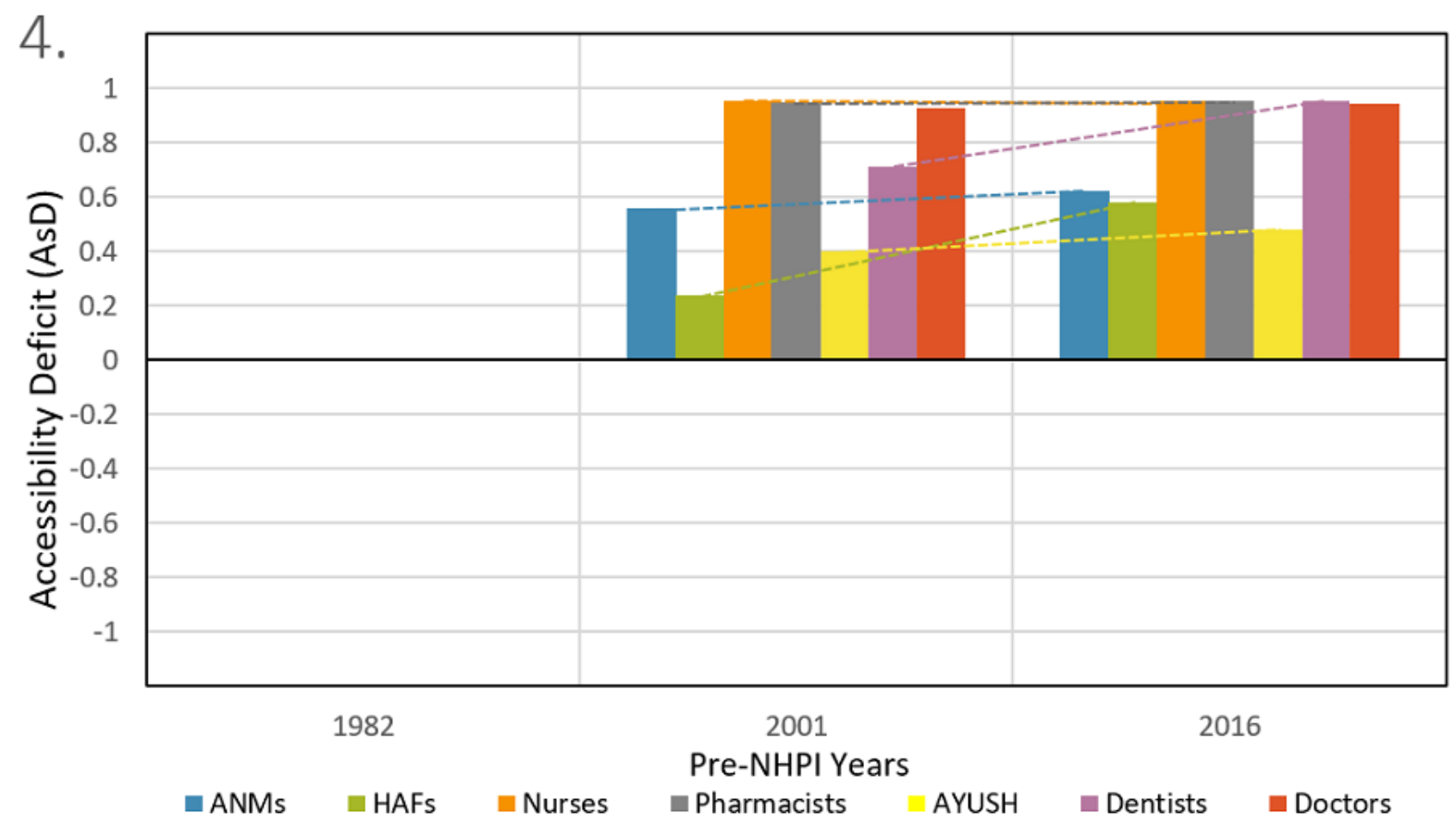

Figure 4 
Accessibility Deficit (AsD) for pre-NHPI years 2001 and 2016 according to Bhore and HLEG norms. Legend - Dashed lines indicate the longitudinal changes in deficit. Truncated bars indicate that the deficit was less than -1 and corresponding values are written on the bars. Accessibility Deficit for 1983 was not calculated due to unavailable present rural HRH data for the corresponding year. NHPI: National Health Policy of India, HRH: Human resources for Health, AYUSH: Ayurveda, Yoga and Naturopathy, Unani, Siddha and Homeopathy, ANMs: Auxiliary Nurse-Midwives, HAFs: Health Assistants Female.
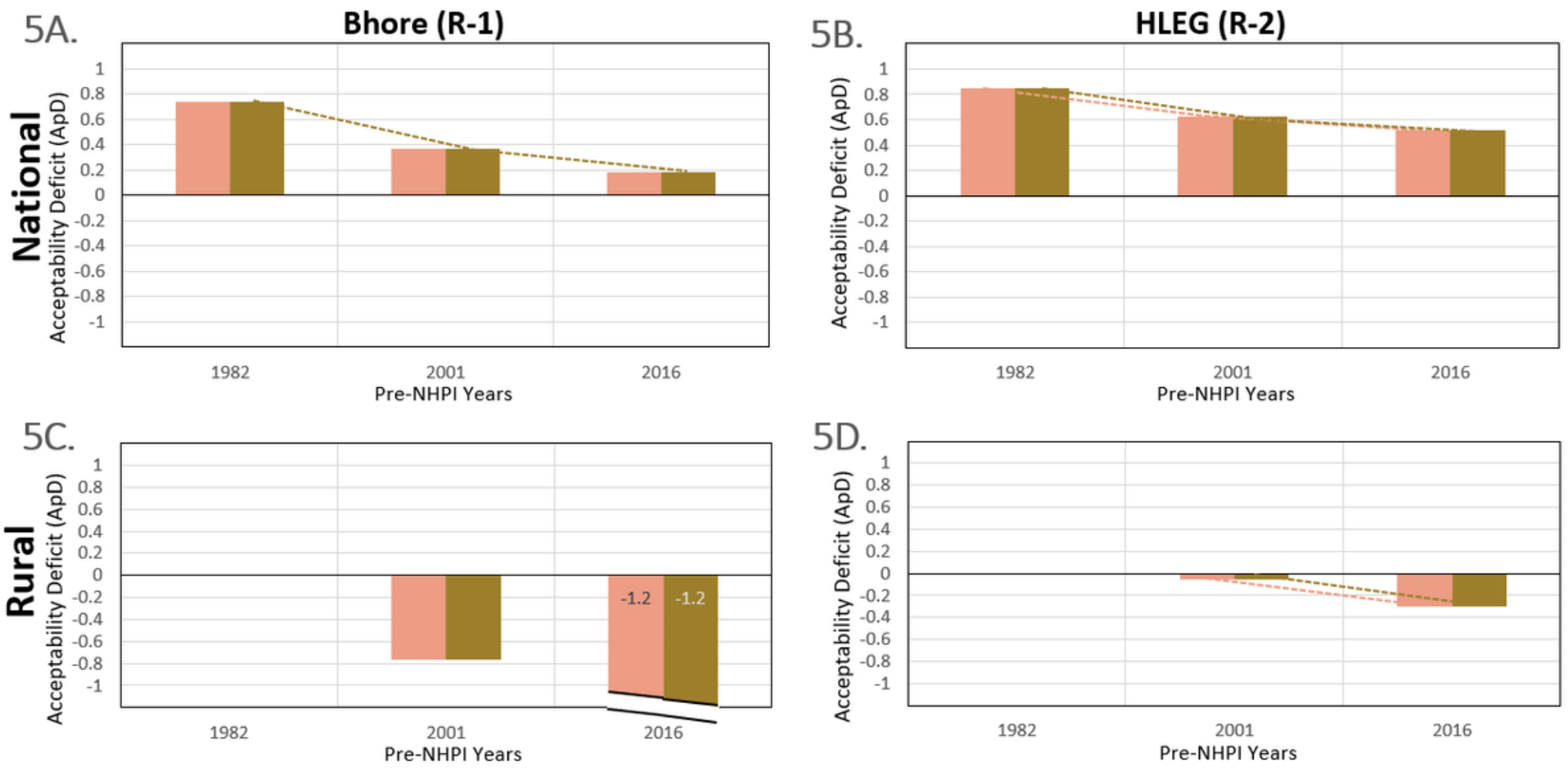

Nursing cadres

- Supporting cadres

\section{Figure 5}

Acceptability Deficit (ApD) for pre-NHPI years 1982, 2001, 2016 according to Bhore and HLEG norms. Legend - Dashed lines indicate the longitudinal changes in Acceptability Deficit. Truncated bars indicate that the deficit was less than -1 and the corresponding values are written on the bars. Nursing cadres include ANMs, HAFs, and nurses. Supporting cadres include pharmacists along with nursing cadres. NHPI: National Health Policy of India.

6.

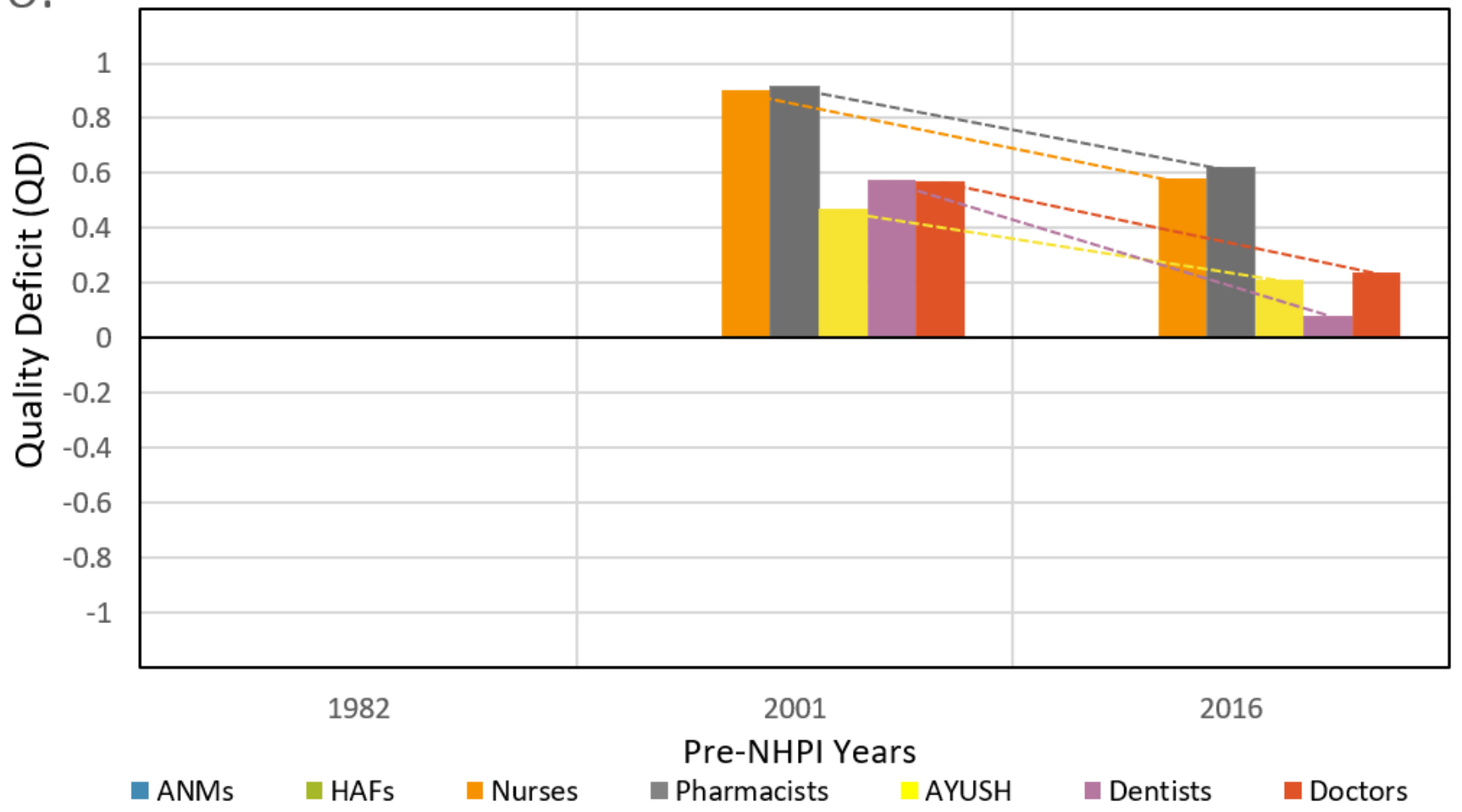

Figure 6 
Quality Deficit (QD) for pre-NHPI years 2001, and 2016. Legend - Quality Deficit for all cadres of 1983, and ANMs and HAFs for 2002 and 2017 as their qualification details were not available. NHPI: National Health Policy of India, HRH: Human resources for Health, AYUSH: Ayurveda, Yoga and Naturopathy, Unani, Siddha and Homeopathy, ANMs: Auxiliary Nurse-Midwives, HAFs: Health Assistants Female.

\section{Supplementary Files}

This is a list of supplementary files associated with this preprint. Click to download.

- GHRPSDnhpadditionalfile1.xlsx

- GHRPSDnhpadditionalfile2.docx 